\title{
Fluorine Content of Teas Consumed in New Zealand
}

\author{
BY MARION F. HARRISON \\ Department of Nutrition Research, Otago Medical School, Dunedin, \\ New Zealand
}

(Received 26 October 1948)

Before the rationing of tea was introduced, New Zealand had the third largest annual consumption of tea in the world, namely $8.2 \mathrm{lb}$./person. Subsequently, the ration of $2 \mathrm{oz}$./week with extra concessions to people working in factories and offices provided an annual consumption of $6.5 \mathrm{lb}$./person.

Most foods are found to be poor sources of fluorine, even when grown in fluorinerich soils, supposedly because the fluorine in the soil becomes converted to the insoluble calcium form (Smith, Smith \& Vavich, 1942). Tea, which grows in relatively acidic soils, is exceptional in its faculty for taking up fluorine. As much as $176 \mathrm{mg}$. fluorine/ roo g. dry substance was found by Reid (r936) in a sample of fresh tea from a fluorspar mining area, though two roasted teas from the same area contained only 1.5 and $7 \cdot \mathrm{I} \mathrm{mg}$. fluorine $/ 100 \mathrm{~g}$. dry tea. He found that the fluorine content of Chinese teas varied from 3 to $40 \mathrm{mg}$./ $100 \mathrm{~g}$., whereas Indian and Ceylon teas contained 3.8 and $0.9 \mathrm{mg}$. respectively. Cheng \& Chou (1940) considered that the fluorine content of tea was in the range $0.7-9 \mathrm{mg} . / 100 \mathrm{~g}$.

Reid (1936) found that $8 \mathrm{I}-96 \%$ of the fluorine in tea was extracted from a $2 \%$ infusion in $5 \mathrm{~min}$. Lockwood (1937) extracted $80 \%$ of the fluorine in an infusion made from tea containing 70 p.p.m. fluorine. Clifford (1945) reported the mean result of analyses of tea infusions in ten field stations as $1 \cdot 19$ p.p.m.

Since tea is an important item in the New Zealand diet, and the water supplies are low in fluorine (Chamberlain, 1944, 1946; Denmead, 1946), its potentialities as a contributor of fluorine have been thought worthy of investigation.

\section{EXPERIMENTAL}

As a preliminary test, a random sample taken from a commercial brand of tea was analysed. After a lapse of 6 months, an estimation on another packet of the same brand gave a higher fluorine content, the discrepancy being ascribed to a possible difference in blend. Information was therefore sought from the Tea Controller as to the areas from which supplies of tea are drawn for the New Zealand market. Almost all of the tea used is either from Ceylon or from India. The chief districts and qualities are classified into North Indian, Ceylon Common Grade, Choice Ceylon (Fannings Grade). Samples of these types were obtained, and the fluorine content was determined both of the dry teas and of infusions made from them.

The following variations in the strength of infusion were employed for each of the three types of tea: 
(a) $6.75 \mathrm{~g} . / 1$. , which is equivalent to one level teaspoon per $8 \mathrm{oz}$. cup, the quantity recommended as a basis for a standard recipe by the School of Home Science of the University of Otago.

(b) ro.० g./1.; McCance \& Widdowson (1946) used this strength of tea infusion when preparing Chemical Composition of Foods for the Medical Research Council.

(c) $15.0 \mathrm{~g} . / \mathrm{l} .$, the quantity used by Clifford (1945).

Since the strength of an infusion used domestically depends not only on personal taste but also on the variety of tea, the quantities selected for investigation were judged suitable for covering the range for the majority of tastes and varieties.

As a guide to the effect of duration of infusion on the amount of fluorine extracted, each sample was infused for 3 and ro $\mathrm{min}$.

For the analyses of teas, the leaves were first ground to 60-mesh. To the weighed sample, contained in a platinum crucible, was added $\mathrm{r}$ ml. magnesium acetate solution $\left(25 \% \mathrm{w} / \mathrm{v} \mathrm{Mg}\left(\mathrm{CH}_{3} \mathrm{COO}\right)_{2} .4 \mathrm{H}_{2} \mathrm{O}\right)$ and sufficient $20 \%$ (w/v) sodium hydroxide to make the mixture alkaline to phenolphthalein (Crutchfield, 1942). After evaporation to dryness on a water-bath, the residue was ashed at $500^{\circ}$ in a muffle furnace. The ash was wetted with fluorine-free distilled water and again dried and ashed, this procedure being repeated until a white ash resulted. The fluorine was estimated by the distillation and colorimetric titration methods of Dahle, Bonnar \& Wichmann (1938) and Van der Merwe (1940), modified as described for analyses of teeth and urine (Harrison, 1949a,b).

The infusions were prepared with tap water, filtered and, when cold, made up to volume with fluorine-free distilled water. A portion was taken for analysis, the methods for ashing, distillation and colorimetric estimation being identical with those described above for the dry tea.

RESULTS

The values obtained are given in Tables $1-3$.

Table I. Fluorine and water content of tea

Variety of tea

Sample I, Brand A, April 1947

Sample I I, Brand A, November 1947

Indian

Ceylon Common

Choice Ceylon

$\begin{array}{cccc}\begin{array}{c}\text { No. of } \\ \text { analyses }\end{array} & \begin{array}{c}\text { Water } \\ (\%)\end{array} & \begin{array}{c}\text { In sample } \\ \text { In dry matter }\end{array} \\ 3 & - & 6.8 & - \\ 8 & 7.9 & 10.4 & 11.3 \\ 3 & 8.9 & 9.2 & 10.1 \\ 8 & 5.7 & 14.3 & 15.2 \\ 6 & 5.0 & 14.7 & 15.5\end{array}$

Table 2. Fluorine content of tea infusions
Fluorine in tea (p.p.m.)

$\begin{array}{cccc}\text { Brand A } & \text { North Indian Ceylon Common Choice Ceylon } \\ 0.46 & 0.54 & 0.72 & 0.75 \\ 0.48 & 0.57 & 0.77 & 0.76 \\ - & 0.70 & 1.02 & 0.95 \\ - & 0.84 & 1.06 & 0.93 \\ 0.82 & 1.04 & 1.54 & 1.26 \\ 0.91 & 1.15 & 1.69 & 1.30\end{array}$


Table 3. Percentage extraction of fluorine from teas

\begin{tabular}{|c|c|c|c|c|c|}
\hline \multicolumn{2}{|c|}{ Infusion } & \multicolumn{4}{|c|}{ Extraction of fluorine from tea $(\%)$} \\
\hline $\begin{array}{l}\text { Strength } \\
\text { (g./l.) }\end{array}$ & $\begin{array}{c}\text { Duration } \\
\text { (min.) }\end{array}$ & Brand A & North Indian & Ceylon Common & Choice Ceylon \\
\hline 6.75 & $\begin{array}{r}3 \\
10\end{array}$ & $\begin{array}{l}100 \\
104\end{array}$ & $\begin{array}{l}88 \\
92\end{array}$ & $\begin{array}{l}74 \\
80\end{array}$ & $\begin{array}{l}75 \\
76\end{array}$ \\
\hline $10 \cdot 0$ & $\begin{array}{r}3 \\
10\end{array}$ & $\overline{-}$ & $\begin{array}{l}77 \\
92\end{array}$ & $\begin{array}{l}71 \\
74\end{array}$ & $\begin{array}{l}65 \\
63\end{array}$ \\
\hline $15 \cdot 0$ & $\begin{array}{r}3 \\
10\end{array}$ & $\begin{array}{l}80 \\
90\end{array}$ & $\begin{array}{l}76 \\
84\end{array}$ & $\begin{array}{l}72 \\
79\end{array}$ & $\begin{array}{l}57 \\
59\end{array}$ \\
\hline
\end{tabular}

\section{DISCUSSSION}

Wide variations were found in the fluorine content of the teas examined. In contrast to the findings of Reid (1936), the Indian tea analysed had a lower fluorine content than the Ceylon tea. The explanation for the variable figures may lie in the type of soil in the area where the tea was grown.

Since teas are blended according to their flavours when infused with tap water, the tea infusions were prepared with tap water. As the fluorine content of the municipal water supply in Dunedin is very low (0.05 P.p.m.), the meagre amount of fluorine that it would contribute to the tea infusions was not deducted in calculating the percentage extraction of fluorine from the teas.

Four separate tea infusions were prepared of each weight of tea and for each duration of infusion. The results from the analyses of comparable infusions agreed.

With increase in length of infusion time there was a consistent, slight increase in fluorine content of the tea infusion from three brands. Whereas the North Indian and Brand A tea infusions increased somewhat, Choice Ceylon showed a slight decrease in the estimation on a $10 \mathrm{~g} . / 1$. infusion, and a slight increase in the $15 \mathrm{~g}$./l. infusion, though the differences for the last named brand were not significant.

The usual practice of tea-tasters is to infuse tea for $5 \mathrm{~min}$.; this produces the best flavour, with little extraction of tannin. On the other hand, as these results show, most of the fluorine would be extracted in this time.

When stronger infusions of tea are prepared, the fluorine content rises, but not proportionately to the increase in strength. There is a definite tendency towards a decrease in extraction with increase of tea infusion.

Table 4 gives the values for the daily intake of fluorine from the various teas, calculated from the daily ration of $8.1 \mathrm{~g}$. tea, and from the values for extraction found in Table 3.

From these calculations, the daily ration of tea provides a quantity of fluorine which varies, according to the variety and the duration of infusion, from 0.45 to $0.93 \mathrm{mg}$. The optimal intake of fluorine for protection from dental caries has been suggested as I mg. fluorine/day from water where it is presumably in the form of sodium fluoride (Dean, 1943; Ockerse, 194I; Weaver, 1944; and others).

If fluorine is a factor in the prevention of dental caries, and if its protective effect is due to the formation of a more resistant enamel, it is necessary that this amount of 
fluorine be absorbed during the calcification of the teeth, especially during the first 8 years of life. In general, however, tea is not consumed in quantities until later in life, and no justification can be found for replacing protective foods, such as milk, by quantities of tea in the diet of the growing child. If fluorine ingested can be taken up

\section{Table 4. Daily fluorine intake provided by official ration of tea}

\begin{tabular}{|c|c|c|c|c|c|}
\hline \multicolumn{2}{|c|}{ Infusion } & \multicolumn{4}{|c|}{ Fluorine provided by tea (mg.) } \\
\hline $\begin{array}{l}\text { Strength } \\
\text { (g./1.) }\end{array}$ & $\begin{array}{c}\text { Duration } \\
\text { (min.) }\end{array}$ & Brand A & North Indian & Ceylon Common & Choice Ceylon \\
\hline $6 \cdot 75$ & $\begin{array}{r}3 \\
10\end{array}$ & $\begin{array}{l}0.55 \\
0.57\end{array}$ & $\begin{array}{l}0.66 \\
0.69\end{array}$ & $\begin{array}{l}0.86 \\
0.93\end{array}$ & $\begin{array}{l}0.88 \\
0.89\end{array}$ \\
\hline $10 \cdot 0$ & $\begin{array}{r}3 \\
10\end{array}$ & - & $\begin{array}{l}0.58 \\
0.69\end{array}$ & $\begin{array}{l}0.82 \\
0.86\end{array}$ & $\begin{array}{l}0.77 \\
0.77\end{array}$ \\
\hline I $5 \cdot 0$ & $\begin{array}{r}3 \\
10\end{array}$ & $\begin{array}{l}0.45 \\
0.50\end{array}$ & $\begin{array}{l}0.57 \\
0.63\end{array}$ & $\begin{array}{l}0.84 \\
0.92\end{array}$ & $\begin{array}{l}0.68 \\
0.70\end{array}$ \\
\hline
\end{tabular}

The fluorine contributed by the water supply, namely 0.05 p.p.m. fluorine, has been included in these calculations.

by the teeth in later life, some dental benefit may be derived in New Zealand from the habit of tea drinking, but whether erupted teeth possess this faculty is uncertain. However, when fluorine is present in a beverage to the extent of contributing from about 0.5 to $1 \mathrm{mg}$./day, there can be no great harm in advocating the trial of fluoride solutions containing these amounts, for example during pregnancy and lactation, especially if the quantities of milk and other fluids advocated tend to displace tea as a beverage.

A study of the effect of the ingestion of tea on the quantity of fluorine excreted in the urine of subjects is presented in the following paper (Harrison, 1949b). The fluorine content of a series of New Zealand teeth is reported elsewhere (Harrison, 1949a).

\section{SUMMARY}

I. The fluorine content of teas, as supplied to New Zealand from different districts in Ceylon and India, was determined by a modification of the methods of Dahle et al. (1938) and Van der Merwe (1940).

2. Tea infusions of strengths $6.75,10.0$ and $15 \mathrm{~g} . / 1$. were prepared and analysed.

3. With increase of strength of infusion, there was a definite, though not directly proportional, decrease in percentage extraction of fluorine from tea.

4. When the duration of infusion was extended from 3 to ro min. there was usually a small increase in extraction of fluorine from the leaves.

5. From the figures obtained, it was calculated that tea may contribute from 0.45 to $0.93 \mathrm{mg}$. fluorine/day when the ration allowance is $8 . \mathrm{I} \mathrm{g}$./day.

This study was made with financial support given by the New Zealand Medical Research Council, through the Department of Health, to the Nutrition Research Committee. Very grateful thanks are expressed to Dr Muriel E. Bell of the Nutrition Research Department for her counsel and valuable suggestions; to $\mathrm{Dr} \mathrm{C}$. J. Wilkins, 
Lecturer in Chemistry at Canterbury University College, Christchurch, N.Z., for his guidance and assistance with the method and apparatus for determining fluorine; and to Mr L. M. Wright, Tea Controller, for supplying samples of the teas.

\title{
REFERENCES
}

Chamberlain, G. (1944). N.Z. F. Sci. Tech. 26, sect. B, p. 90.

Chamberlain, G. (1946). N.Z. F. Sci. Tech. 28, sect. B, p. 154.

Cheng, L. T. \& Chou, T. P. (1940). Chin. F. Physiol. 15, 263.

Clifford, P. A. (1945). Э. Ass. off. agric. Chem., Wash., 28, 277.

Crutchfield, W. E. Jr. (1942). Industr. Engng Chem. (Anal. ed.), I4, 57.

Dahle, D., Bonnar, R. U. \& Wichmann, H. J. (1938). F. Ass. off. agric. Chem., Wash., 2 r, 459.

Dean, H. T. (1943). F. Amer. Wat. Whs Ass. 35, 116 r.

Denmead, C. F. (1946). N.Z. Y. Sci. Tech. 28, sect. B, p. 158.

Harrison, M. F. (1949a). N.Z. dent. F. 45, 2.

Harrison, M. F. (1949b). Brit. J. Nutrit. 3, 166.

Lockwood, H. C. (1937). Analyst, 62, 775.

McCance, R. A. \& Widdowson, E. M. (1946). Spec. Rep. Ser. med. Res. Coun., Lond., no. 235, 2nd ed. Ockerse, T. (1941). S. Afr. med. F. 15, $26 \mathrm{I}$.

Reid, E. (1936). Chin. J. Physiol. 10, 259.

Smith, H. V., Smith, M. C. \& Vavich, M. (r942). Quoted by Smith, H. V. (1942). Publ. Amer. Ass. Advance Sci. 19, 12.

Van der Merwe, P. K. (1940). Onderstepoort $\mathcal{~ F . ~ v e t . ~ S c i . ~} 14,359$.

Weaver, R. (1944). Brit. dent. F. 76, 29.

\section{Urinary Excretion of Fluorine in some New Zealand Subjects}

\author{
BY MARION F. HARRISON \\ Department of Nutrition Research, Otago Medical School, Dunedin, \\ New Zealand
}

(Received 26 October 1948)

During recent years much attention has been directed towards the possible relation between a low fluorine intake, and a high incidence of dental caries. In the United States of America drinking water appears to be the main dietary source of fluorine, and the optimal amount of fluorine for prevention of dental caries without producing fluorosis has been suggested as $\mathrm{I} \cdot 0$ p.p.m. (Dean, 1943). On the other hand, fluorosis has occurred where the water supply had I p.p.m. or less, in England (Bromehead, Murray \& Wilson, 1943), and in Morocco (Murray \& Wilson, I948). This is possibly caused by an inadequate diet or by the inclusion in the diet of some other major contributor of fluorine as, for example, fish or tea (Reid, 1936; Klement, 1938; Harvey, 1945; Clifford, 1945).

However, in New Zealand, of the potable waters so far examined, only one, supplying but a small number of inhabitants, has a fluorine content of more than 0.5 p.p.m., most of the contents being in the range $0.05-0.3$ p.p.m. (Chamberlain, 1944, 1946; Denmead, 1946).

Machle, Scott \& Largent (1942) showed that a normal experimental subject on an unselected diet maintained an equilibrium between fluorine intake and output at 